\title{
Stimulatory Beetle Volatiles for the Asian Longhorned Beetle, Anoplophora glabripennis (Motschulsky)
}

\author{
Aijun Zhang ${ }^{\mathrm{a}, *}$, James E. Oliver ${ }^{\mathrm{a}}$, Jeffrey R. Aldrich ${ }^{\mathrm{a}}$, Baode Wang ${ }^{\mathrm{b}}$ and \\ Vic C. Mastro ${ }^{b}$ \\ a USDA, ARS, Chemicals Affecting Insect Behavior Laboratory, BARC-West, Beltsville, \\ Maryland 20705, U.S.A. Fax: (301)-504-6580. E-mail: zhanga@ba.ars.usda.gov \\ b USDA, APHIS, Plant Protection Center, Otis ANGB, Massachusetts 02542, U.S.A. \\ * Author of correspondance and reprint requests \\ Z. Naturforsch. 57c, 553-558 (2002); received December 10, 2001/January 31, 2002 \\ Anoplophora glabripennis, Electroantennographic Detection, Dialkyl Ether \\ Two male-specific beetle volatiles were found that elicited strong gas chromatographic- \\ electroantennographic responses from both sexes of Asian longhorned beetle adults, Anoplo- \\ phora glabripennis. The secretion consisted of a $\sim 1: 1(\mathrm{v} / \mathrm{v})$ blend of functionalized dialkyl \\ ethers, 4-(n-heptyloxy)butanal and 4-(n-heptyloxy)butan-1-ol. These compounds are chemi- \\ cally unusual natural products that are previously unknown from insects. Laboratory olfacto- \\ meter studies showed that a blend of $10 \mu \mathrm{g}$ of each synthetic compound on a filter paper \\ strip was significantly attractive to ALB adults.
}

\section{Introduction}

Anoplophora glabripennis (Motschulski), the Asian longhorned beetle (ALB), has been inadvertently exported from Asia, probably China, into the United States and Europe via untreated wooden packing material used in international cargo (Milius, 1999). This invasive species was first discovered in New York City in 1996 (Anonymous, 1996), in Chicago in 1998 (Anonymous, 1998), and then in Braunau (upper Austria) in 2001 (Anonymous, 2001).

The ALB belongs to the family Cerambycidae, known as hardwood-borers, in the subfamily Laminae whose species usually attack living trees. $A$. glabripennis seems to prefer to attack maple (Acer) and horse chestnut (Aesculus hippocastanum) in the U.S., and Norway maple (A. platanoides) in the Austria, but is also known to infest poplar (Populus), willow (Salix), elm (Ulmus), mulberry (Morus), and black locust (Robinia pseudoacacia) in its native distribution of eastern China, Japan, and Korea (Anonymous, 1996; Knodel, 1997). Besides maple (Acer) and horse chestnut (Aesculus hippocastanum) in the United States, a wide variety of other trees may also attract $A$. glabripennis. In the laboratory, A. glabripennis will oviposit on cut logs of red oak (Quercus rubra) and can survive at least 90 days after implantation as a first instar larva under the bark of red oak (Hoover et al., personnel communication). A. glabripennis has enormous destructive potential because it spends most of its life as a grub inside tree trunks or branches, larval boring in the trunk and large branches inhibit the tree's vascular system and cause severe damage and eventually tree breakage and death (Cavey et al., 1998). So far no natural enemies that effectively control this pest have been identified (Milius, 1999). Soil injection, trunk injection, and bark spray of certain pesticides were found to be effective for ALB control (McLane et al., 2000); however, the utilization of these technologies may be limited to urban forestry. Efforts to control or eradicate this exotic species have led to removal and destruction of all trees showing symptoms of attack in Chicago and New York City (Anonymous, 1998; Haack et al., 1997). These eradication efforts are already costing many millions of dollars annually but, should the ALB escape eradication, estimates of damage to forestry and the nursery industry run well into the billions of dollars.

To date, detection of $A$. glabripennis infestation relies on visual inspection for adult beetles or for signs of their emergence from trees, procedures which are believed to detect at best only $~ 30 \%$ of the infested trees (Milius, 1999). In an attempt to identify and develop an attractant that would be useful for detection and monitoring of this insect, we collected and analyzed airborne volatiles of $A$. 
glabripennis. Comparison of gas chromatograms of volatiles trapped from the individual sexes maintained on twigs of a favored host, Norway maple, and from the maple twigs alone, enabled us to distinguish between compounds of insect or plant origin, and whether, in the former case, they were common to both sexes or were sex-specific. Because only limited numbers of beetles were available, with none available for field studies, we relied on gas chromatography coupled with electroantennographic detection (GC-EAD) to focus on compounds eliciting a neural response in the beetle. Although an antennal response is not necessarily a predictor of behavior, it is reasonable to expect that most, if not all, volatile compounds capable of eliciting a behavioral response would also stimulate an antennal response. Indeed, the laboratory bioassays conducted do confirm that the identified compounds are behaviorally active.

\section{Results and Discussion}

\section{A. glabripennis volatiles}

Two EAD-active compounds, absent from samples derived from females or maple twigs alone, appeared in volatiles from adult male beetles (Fig. 1). Each compound elicited EAD-responses from both male and female beetles (Fig. 2B). No close matches for their EI-MS were retrieved from the Wiley 275 mass spectral database. Molecular weights (mw's) of the two unknowns were determined by chemical ionization mass spectrometry

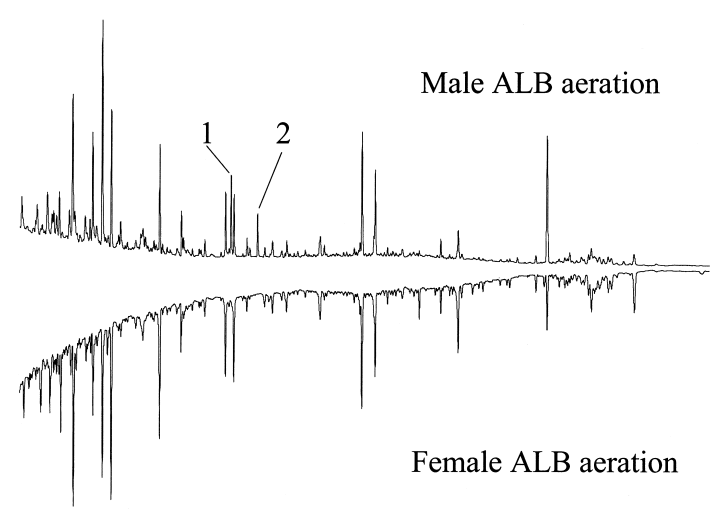

Fig. 1. Gas chromatograms (FID detection) of aeration extracts of male (top) versus female (bottom) Asian longhorned beetle, A. glabripennis (groups of 6 beetles aerated 24 hours). Two male-specific compounds are indicated as $\mathbf{1}$ and $\mathbf{2}$.
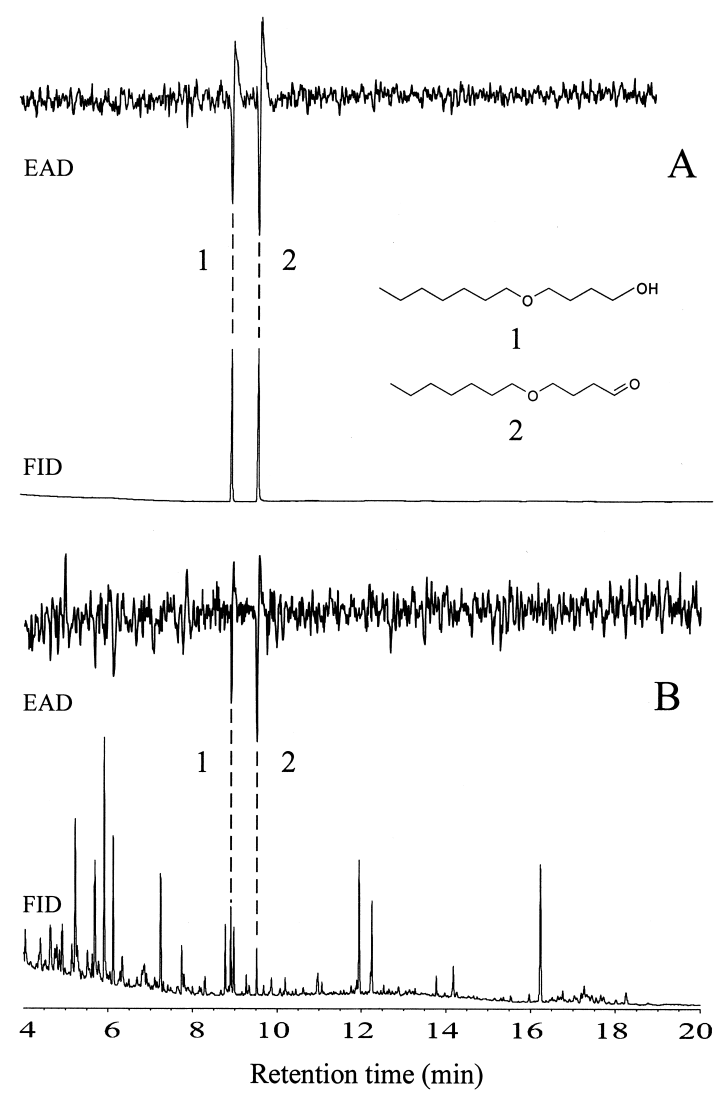

Fig. 2. Simultaneous flame ionization detector (FID) and electroantennographic detection (EAD) responses of an adult male $A$. glabripennis antenna to A) a mixture of synthetic 1 and 2 (50 ng each compound, 1:1 ratio, v/v), and B) volatiles trapped from male A. glabripennis.

(CI-MS) obtained with ammonia $\left(\mathrm{NH}_{3}\right)$ as reagent gas as mw $186\left(m / z \quad 187 \quad[\mathrm{M}+\mathrm{H}]^{+}, m / z \quad 204\right.$ $\left.\left[\mathrm{M}+\mathrm{NH}_{4}\right]^{+}\right)$and $\mathrm{mw} 188\left(\mathrm{~m} / \mathrm{z} 189[\mathrm{M}+\mathrm{H}]^{+}, 206\right.$ $\left[\mathrm{M}+\mathrm{NH}_{4}\right]^{+}$), respectively. Comparison of CI-MS obtained with deuteroammonia $\left(\mathrm{ND}_{3}\right)$ indicated that the mw 188 compound contained a single exchangeable hydrogen $(m / z) 191[\mathrm{M}-\mathrm{H}+2 \mathrm{D}]^{+}, m / z$ $\left.211\left[\mathrm{M}-\mathrm{H}+\mathrm{D}+\mathrm{ND}_{4}\right]^{+}\right)$, whereas in the $\mathrm{mw} 186$ compound no hydrogens were exchanged $(\mathrm{m} / z 188$ $\left.[\mathrm{M}+\mathrm{D}]^{+}, m / z, 208\left[\mathrm{M}+\mathrm{ND}_{4}\right]^{+}\right)$. The electron ionization MS of the mw 188 compound resembled that of an aliphatic alcohol except for the curious "doubling" of several alkyl fragments $(\mathrm{m} / \mathrm{z}, 41 / 43,55 /$ $57,71 / 73$ ) that was observed to resemble a similar phenomenon in the spectrum of 2-(n-butoxy)ethanol and ultimately was explained by the presence of an ether oxygen in the otherwise unsubstituted 
chain. 4-(n-Heptyloxy)butan-1-ol (2) was synthesized and found to be identical (GC on polar and non-polar capillary columns, GC-MS) to the natural product. Swern oxidation (Mancuso et al., 1978) provided the aldehyde $\mathbf{1}$ which was identical in all respects to the second unknown. Synthetic $\mathbf{1}$ and $\mathbf{2}$ each stimulated strong antennal responses from both male and female beetles (Fig. 2A).

Although simple compounds, ethers $\mathbf{1}$ and $\mathbf{2}$ appear to be unique as natural products. Aldehyde $\mathbf{1}$ has appeared once previously in the literature, but only as the product of synthetic methodology (Coutrot and Savignac, 1977). Dialkyl ethers appear to be very uncommon as insect-produced products (Hardie and Minks, 1999; Mori, 1992). The methoxyacetamide of 3-methylbutylamine has been reported from males of two species of fruit flies in the genus Bactrocera (Fletcher and Kitching, 1995). Cyclic ethers, particularly cyclic ketals, are relatively common, and a few alkyl aryl ethers have been reported, but they can all be envisioned as products of quite different biosynthetic sequences than those likely to be utilized for dialkyl ether biosynthesis.

During collection of volatiles, compounds $\mathbf{1}$ and $\mathbf{2}$ were detectable in all samples from male beetles but were undetectable in samples from female beetles. The concentrations seemed to increase from barely detectable levels in volatiles from newly emerged males to $\sim 30 \mathrm{ng} / \mathrm{male} /$ day at about 10 days; older males have not been examined.

\section{Olfactometer bioassay}

In the olfactometer bioassay, a dosage study indicated that the lower and upper stimulant thresholds were critical. It was found that more beetles were attracted to the 10 and $20 \mu \mathrm{g}$ lures than to the lower and higher doses (Fig. 3). Therefore $20 \mu \mathrm{g}$ of the $1: 1(\mathrm{v} / \mathrm{v})$ blend was chosen for the remaining experiments.

The time required for a beetle to reach the treatment or control chambers varied greatly. Some beetles walked into the treatment chamber in less than two minutes whereas others required as much as twenty minutes to reach a chosen chamber. In total, 69 beetles were tested at the optimized dosage $(20 \mu \mathrm{g}$ of the 1:1 synthetic blend), of which $52 \%$ were attracted by the stimulant blend. Of beetles that made a choice, the stim-

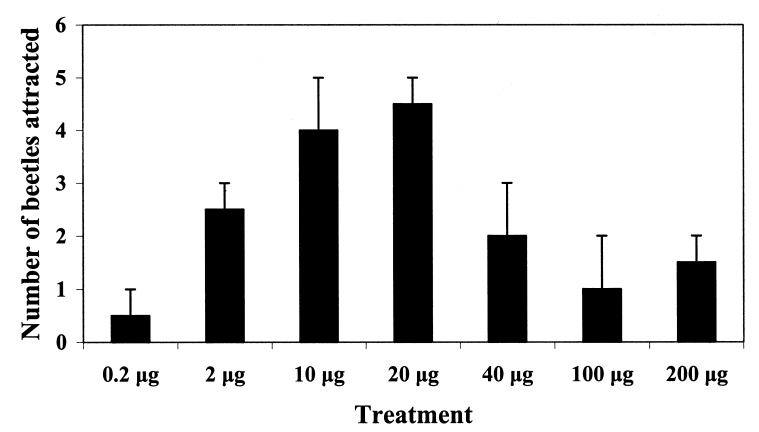

Fig. 3. Attraction of male A. glabripennis in an olfactometer baited with synthetic stimulus blend (1:1 ratio, $\mathrm{v} / \mathrm{v})$ at seven doses (10 replicates for each dosage).

ulus was significantly preferred over the control chamber, but neither stimulus nor control vs. nochoice beetles was significantly different (Chisquare goodness of fit test: Chi-Square $=13.87$, $\mathrm{df}=2, p$-value $\S 0.0008)$. No statistical differences in response were detected between different age groups of ALBs, or between female vs. male responses to the synthetic blend.

\section{Experimental}

Insects

Virgin A. glabripennis adults, collected as larvae or pupae in logs from infestation areas in Chicago and New York City, were maintained in the quarantine facility of the U. S. Department of Agriculture, Otis Plant Protection Center located in Massachusetts. Adults were collected daily upon emergence in April 1999, and separated by sex; most beetles were therefore believed to be unmated, but occasional mating was observed almost immediately upon emergence. Adults were maintained individually in 2-liter plastic bottles containing a water cup and twigs of $A$. platanoides in a rearing room maintained at $16 \mathrm{~L}: 8 \mathrm{D}, 25^{\circ} \mathrm{C}$, and $\sim 60 \%$ relative humidity.

\section{Volatiles collection}

Groups of ten 1-day-old male and female A. glabripennis were separately introduced into 1-liter, 4-necked glass containers (Zhang et al., 1994) containing freshly cut twigs of $A$. platanoides in a water cup. Air was drawn into the container through 6-14 mesh activated charcoal (Fisher Sci- 
entific, Pittsburgh, PA), and out of the container through two traps (15 cm X 1.5-cm OD) containing Super Q (200 mg each; Alltech Associates, Inc., Deerfield, IL) using a water aspirator or vacuum pump ( 1 liter/min). Beetles were aerated continuously for 8-10 days, and adsorbents were changed every 24 hours. The adsorbents were eluted with methylene chloride $(4 \mathrm{X} 0.5 \mathrm{ml})$; the eluates were concentrated and stored at $-4{ }^{\circ} \mathrm{C}$ until use. The same system, but without beetles, was used for collection of plant volatiles.

\section{Instrumentation}

The coupled GC-EAD system used was as previously described (Zhang et al., 1999; Zhang et al., 1997) with a few modifications. A Hewlett Packard 6890 gas chromatograph equipped with a $60 \mathrm{~m}$ X 0.25-mm ID, 0.25- $\mu \mathrm{m}$ film-thickness DB-5 or DB-WAXetr capillary column (J\&W Scientific Inc., Folsom, CA) in the splitless mode with nitrogen as carrier $(2 \mathrm{ml} / \mathrm{min})$ was used for GC-EAD analysis $\left(50{ }^{\circ} \mathrm{C}\right.$ for $2 \mathrm{~min}$, then programmed to $230^{\circ} \mathrm{C}$ at $10^{\circ} \mathrm{C} / \mathrm{min}$ and held for $10 \mathrm{~min}$ ). An acrylic well type holder connected to a high-impedance 1:100 amplifier with automatic baseline drift compensation was employed, and the antennal preparation was cooled to $\sim 5^{\circ} \mathrm{C}$ inside a condenser by circulating near $0^{\circ} \mathrm{C}$ water from a benchtop refrigeration unit (RTE-100, NESLAB instruments, Inc., Portsmouth, NH). The flame ionization and electrophysiological output signals were recorded using Hewlett-Packard ChemStation software. Identical units were assembled and used in the Chemicals Affecting Insect Behavior Laboratory, Beltsville, MD, where some of the work using male beetles was done, and in the Otis Plant Protection Center quarantine facility, MA, where experiments with both sexes were conducted.

Gas chromatography-mass spectrometry (GCMS) was conducted on a Hewlett-Packard 6890 coupled to a HP 5973 Mass Selective Detector (EI) using an identical GC column and conditions but with helium as carrier. Chemical ionization (CI) spectra were obtained from a Finnigan Model 4510 GC-MS with ammonia or deuteroammonia as reagent gases.

\section{Chemicals}

4-(n-Heptyloxy)butan-1-ol (2) was prepared by Williamson synthesis. A solution of butane-1,4diol (180 g, 2 mol) in dry N,N-dimethylformamide (1 liter) was stirred under a nitrogen atmosphere and cooled with an ice bath while sodium hydride (60\% in mineral oil, $76 \mathrm{~g}, 1.9 \mathrm{~mol}$ ) was added in portions over about 10 minutes. The solution was slowly heated to $60^{\circ} \mathrm{C}$, then again cooled and a solution of 1-bromoheptane $(190 \mathrm{ml}, 1.21 \mathrm{~mol})$ in dry tetrahydrofuran $(200 \mathrm{ml})$ was added dropwise. After the addition, the solution was again heated to $60-70{ }^{\circ} \mathrm{C}$, then was cooled and added to ice $(1$ $\mathrm{kg})$. The mixture was extracted with ether-hexane $(1: 1,3$ X $200 \mathrm{ml})$, and the combined extracts were rinsed with water (2 X $200 \mathrm{ml})$ and finally with saturated sodium chloride solution (1 X $200 \mathrm{ml}$ ). After drying over magnesium sulfate, the solvent was removed with a rotary evaporator and the residue was distilled to give $156.6 \mathrm{~g}(69 \%)$ of 2, b.p. 88-91 ${ }^{\circ} \mathrm{C}, 0.1$ Torr. ${ }^{1} \mathrm{H}$ NMR (CDCl3, $\left.300 \mathrm{MHz}\right)$ $0.866(3 \mathrm{H}$, distorted $\mathrm{t}, J=7.0 \mathrm{~Hz}, \mathrm{CH} 3), 1.27$ (methylene), 1.51-1.6 (2H, m), 1.63-1.69 (4 H, m), 2.60 (br. s, OH,), 3.41 (2H, t, $J=6.75 \mathrm{~Hz}$, CH2OCH2), $3.44(2 \mathrm{H}, \mathrm{t}, J=5.75 \mathrm{~Hz}, \mathrm{CH} 2 \mathrm{OCH} 2)$, $3.63(2 \mathrm{H}, \mathrm{t}, J=5.25 \mathrm{~Hz}, \mathrm{CH} 2 \mathrm{OH})$; EI-MS $m / z 145$ (5), 115 (16), 98 (10), 97 (25), 89 (44), 73 (67), 71 (97), 70 (15), 69 (12), 57 (100), 56 (25), 55 (99), 44 (20), 43 (72), 42 (29), 41 (62).

4-(n-Heptyloxy)butanal (1) was obtained by Swern oxidation of (2). A solution of oxalyl chloride $(42 \mathrm{ml})$ in dry methylene chloride $(750 \mathrm{ml})$ was cooled under a nitrogen atmosphere to $75^{\circ} \mathrm{C}$. Dimethylsulfoxide $(72 \mathrm{ml})$ was added dropwise with stirring, followed, after ten minutes by a solution of 2 (75.2 g) in methylene chloride $(75 \mathrm{ml})$. The mixture was stirred and allowed to warm to $-45^{\circ} \mathrm{C}$, then was again cooled to $-75^{\circ} \mathrm{C}$ and treated dropwise with triethylamine $(292 \mathrm{ml})$. After the addition was complete, the cooling bath was removed and the mixture was allowed to slowly warm to room temperature and stir one hour. Ice was added, and the product was partitioned between water and methylene chloride. The solvent was removed with a rotary evaporator, and the residue was dissolved in petroleum ether $(500 \mathrm{ml})$ and the solution was rinsed successively with water, cold aqueous hydrochloric acid, water, and saturated aqueous sodium bicarbonate. After 
drying over magnesium sulfate, the solvent was stripped in vacuo, and the residue was distilled to give $57.6 \mathrm{~g}(77 \%)$ of $\mathbf{1}$, b.p. $60{ }^{\circ} \mathrm{C}, 0.25$ Torr. ${ }^{1} \mathrm{H}$ NMR (CDCl3, $300 \mathrm{MHz}) 0.869$ (3 H, distorted t, $J=7.0 \mathrm{~Hz}), 1.27$ (methylene), $1.53(2 \mathrm{H}, \mathrm{m}), 1.90$ $(2 \mathrm{H}, \mathrm{m}), 2.51(2 \mathrm{H}, \mathrm{td}, J=7.0$ and $1.5 \mathrm{~Hz}), 3.37$ $(2 \mathrm{H}, \mathrm{t}, J=6.5 \mathrm{~Hz}, \mathrm{CH} 2 \mathrm{OCH} 2), 3.42(2 \mathrm{H}, J=6.25$ $\mathrm{Hz}, \mathrm{CH} 2 \mathrm{OCH} 2), 9.77$ (1 H, t, $J=1.5 \mathrm{~Hz}, \mathrm{CHO})$; EI-MS m/z 142 (23), 127 (13), 98 (17), 97 (19), 96 (26), 71 (58), 70 (28), 69 (19), 57 (100), 56 (24), 55 (30), 44 (14), 43 (76), 42 (29), 41 (71).

\section{Olfactometer and bioassay}

A typical two-choice olfactometer was used to test biological activity of synthetic samples. Three round-bottom flasks (1 liter, 24/40) were attached to each end of the glass Y-tube $(300 \mathrm{~mm} \mathrm{X} \mathrm{70-}$ $\mathrm{mm}$ OD) with glass joints (71/60) as the sample, treatment, and control chambers. Treatment and control chamber connectors were connected to a T-tube using silicon tubing $(5.0 \mathrm{~mm} \mathrm{ID,} 9.5 \mathrm{~mm}$ OD, Silastic ${ }^{\circledR}$ laboratory tubing, VWR Scientific Products Corp., San Francisco, CA) and the end of this T-tube was then connected to a water bubbler and charcoal trap (Activated carbon, 6-14 mesh, Fisher Scientific, Pittsburgh, PA; $40 \mathrm{~mm} \mathrm{X}$ $20 \mathrm{~mm}-\mathrm{OD})$. The release chamber was connected to a vacuum pump through a flow meter (Accura Flow Products Inc., Hatboro, PA) adjusted to a flow rate at $\sim 1$ liter/min. Two identical apparatuses were positioned horizontally on a table in the center of the room $\left(22-23{ }^{\circ} \mathrm{C}, \sim 60 \%\right.$ relative humidity) with three incandescent lights $(40 \mathrm{~W} / \mathrm{each}) \mathrm{di}$ rectly above the olfactometers $\sim 1.5$ meters.

A dosage study was conducted in order get the lower and upper stimulant thresholds. The filter paper strips were baited with 0.2, 2, 10, 20, 40, 100, and $200 \mu \mathrm{g}$ of a 1:1 blend of the synthetic malespecific compounds, and each dosage was tested two times on two different days with a group of five males. A total of ten replicates were performed using each dosage and a blank as a control.

At the optimized dose, beetles of various ages were tested; the youngest was 1-day-old (newly emerged) and the oldest was 51-day-old. Both males and females were used as available. A total of 69 replicates (17 males and 52 females) were performed using 1 beetle per replicate to prevent fighting between males or attempting to mate between males and females. Twenty $\mu \mathrm{g}$ of synthetic male-specific stimulus $\mathbf{1}$ and $\mathbf{2}$ ( $1 \mu$ l hexane solution, $10 \mu \mathrm{g} / \mu \mathrm{l}$ each, $1: 1 \mathrm{ratio})$ were loaded on a filter paper strip, which was placed into the treatment chamber connector. As a control, the same volume of hexane on a filter paper strip was placed into the control chamber connector. Beetles were removed from their rearing bottles and released into the end of the Y-tube (release chamber side) and observed for a period of $20 \mathrm{~min}$; beetles that did not complete the entire upwind walking choice within twenty minutes, or did not move at all, were counted as "no choice". After each assay, the beetle was removed and a new beetle was introduced. Treatment and control chambers were alternated every two assays to randomize uneven environmental factors.

\section{Statistical analysis}

The A. glabripennis responses were analyzed using StatXact 4 (Cytel Software) to calculate exact $p$-values for the choices (Metha and Patel, 2000). All beetles' responses were analyzed in three ways: choice, choice by sex, and choice by age. When overall statistical significance was found, Chi-square tests were used to compare pairs of cells to determine if they were different. Sidak adjusted $p$-values were used for the comparisons so that the overall significance level was 0.05 .

\section{Acknowledgements}

We thank Mr. Dave DeVilbiss and Mr. Vic Levi of the Chemicals Affecting Insect Behavior Laboratory for assistance with syntheses and obtaining mass spectral data, Ms. Junying Nie for laboratory bioassay, Dr. Walter Schmidt, Environmental Chemistry Laboratory, for NMR spectra, and Dr. Mary Camp, Biometrical Consulting Service, for statistical analysis. Thanks also go to Ms. Nancy Ellison, and Ms. Barbara Holske, Otis Plant Protection Center, USDA, APHIS, Otis ANGB, MA, for supplying beetles and use of facilities. Mention of trade names or commercial products in this article is solely for the purpose of providing specific information and does not imply recommendation or endorsement by the U. S. Department of Agriculture. 
Anonymous (1996), NPAG Report on Asian Longhorned Beetle. USDA-APHIS.

http://www.aphis.usda.gov/ppq/bbnpag.html

Anonymous (1998), The Asian Long-horned Beetle. Illinois Department of Agriculture.

http://www.agr.state.il.us/beetle.html

Anonymous (2001), Asiatischer Bockkäfer in Österreich eingeschleppt! witasek. http://www.stadtbaum.at/cpag/109.html

Cavey J. F., Hoebeke E. R., Passoa S. and Lingafelter S. W. (1998), A new exotic threat to North American hardwood forests: An Asian longhorned beetle, Anoplophora glabripennis (Motschulsky) (Coleoptera: Cerambycidae). I. Larval description and diagnosis. Proc. Entomol. Soc. Wash. 100, 373-381.

Coutrot P. and Savignac P. (1977), Carbanions a-phosphoramidés. V. Synthese d' aldéhydes à partir de Nméthyl N-allkyl phosphoramdes. J. Chem. Res.3401, 3408-3409.

Fletcher M. T. and Kitching W. (1995), Chemistry of fruit flies. Chem. Rev. 95, 789-828.

Haack R. A., Law K. R., Mastro V. C., Ossenbruggen H. S. and Raimo B. J. (1997), New York's battle with the Asian long-horned beetle. J. Forestry 95, 11-15.

Hardie J. and Minks A. K. (1999), Pheromones of nonlepidopteran insects associated with agricultural plants. CABI Publishing, New York

Knodel J. J. (1997), Biomeric survey for Asian longhorned beetle 1997 final report. National Agriculture Pest Information System (NAPIS). http://ceris.purdue.edu/napis/pests/alb/survey/alhb1997.html

Mancuso A. J., Huang S. L. and Swern D. (1978), Oxidation of long-chain and related alcohols to carbonyls by dimethyl sulfoxide äctivated" by oxalyl chloride. J. Org. Chem. 43, 2480-2482.
McLane W., Wang B., Cowan D. and Mastro V. (2000), Pesticide research and pilot studies for control of the Asian longhorned beetle, 2000 Annual GYPSY Moth Review, Norfolk, Virginia, pp. 226-230, October 30November 2.

Metha C. and Patel N. (2000), StatXact 4 for Windows: User Manual. 4 ed. Cytel Software Corporation, Cambridge, pp. 941

Milius S. (1999), Son of long-horned beetles. Science News 155, 380-382

Mori K. (1992), The Synthesis of Insect Pheromones, 1979-1989. In: The Total Synthesis of Natural Products (Apsimon J., ed.). Wiley and Sons, New York, pp. $119-120$.

Zhang A., Facundo H. T., Robbins P. S., Linn C. E., Jr., Hanula J. L., Villani M. G. and Roelofs W. L. (1994), Identification and synthesis of female sex pheromone of oriental beetle, Anomala orientalis (Coleoptera: Scarabaeidae). J. Chem. Ecol. 20, 2415-2427.

Zhang A., Linn C. E., Jr., Wright S., Prokopy R., Reissig W. and Roelofs W. L. (1999), Identification of a new blend of apple volatiles attractive to the apple maggot, Rhagoletis pomonella. J. Chem. Ecol. 25, $1221-$ 1232.

Zhang A., Robbins P. S., Leal W. S., Linn C. E., Jr., Villani M. G. and Roelofs W. L. (1997), Essential amino acid methyl esters: Major sex pheromone components of the cranberry white grub, Phyllophaga anxia (Coleoptera: Scarabaeidae). J. Chem. Ecol. 23, 231-245. 